\title{
Investigation on Physico-Chemical Properties of $100 \%$ Cotton Woven Fabric Treated with Titanium Dioxide
}

\author{
Md. Mostafizur Rahman ${ }^{1, ~ *, ~ E l i a s ~ K h a l i l ~}{ }^{1}$, Md. Solaiman ${ }^{1}$, Mubarak Ahmad Khan ${ }^{2}$, Joy Sarkar ${ }^{3}$, \\ Faisal Abedin ${ }^{4}$, A. H. M. Asif Kamal', Rajib Al Mamun ${ }^{6}$ \\ ${ }^{1}$ Department of Textile Engineering, World University of Bangladesh, Dhaka, Bangladesh \\ ${ }^{2}$ Institute of Radiation \& Polymer Technology, Bangladesh Atomic Energy Commission, Dhaka, Bangladesh \\ ${ }^{3}$ Department of Textile Engineering, Khulna University of Engineering \& Technology, Khulna 9203, Bangladesh \\ ${ }^{4}$ Department of Textile Engineering, BGMEA University of Fashion and Technology, Dhaka, Bangladesh \\ ${ }^{5}$ Department of Textile Engineering, Sonargaon University, Tejgaon, Dhaka, Bangladesh \\ ${ }^{6}$ Department of Textile Engineering, Khwaja Yunus Ali University, Sirajgonj, Bangladesh
}

\section{Email address:}

mostafiz_textile@yahoo.com (Rahman M. M.), eliaskhali152@gmail.com (Khalil E.), solaimanbari@gmail.com (Solaiman M.), makhan.inst@gmail.com (Khan M. A.), joy.ctet@gmail.com (Sarkar J.), engnr.faisal.butex@gmail.com (Abedin F.), abirasifkamal@gmail.com (Kamal A. H. M. A.), rajibtexmbstu@yahoo.com (Mamun R. A.)

\section{To cite this article:}

Md. Mostafizur Rahman, Elias Khalil, Md. Solaiman, Mubarak Ahmad Khan, Joy Sarkar, Faisal Abedin, A. H. M. Asif Kamal, Rajib Al Mamun. Investigation on Physico-Chemical Properties of 100\% Cotton Woven Fabric Treated with Titanium Dioxide. American Journal of Applied Chemistry. Vol. 3, No. 2, 2015, pp. 65-68. doi: 10.11648/j.ajac.20150302.15

\begin{abstract}
This paper represents an approach to observe the physico-chemical effects of titanium dioxide $\left(\mathrm{TiO}_{2}\right)$ applied on $100 \%$ cotton woven fabric. Cotton fabric was treated with $\mathrm{TiO}_{2}$ by exhaustion method and followed by necessary curing and washing processes. The treated fabrics were then analyzed by Scanning Electron Microscope (SEM) and the tensile strength, pH and absorbency of the treated and untreated fabrics were examined. It was found that titanium dioxide impairs the hand feel and absorbency of $100 \%$ cotton woven fabrics, wetting time of all treated fabrics increased gradually than untreated fabrics. The treatment increases the tensile strength of $100 \%$ cotton woven fabrics. The treatment with titanium dioxide also kept the $\mathrm{pH}$ of the fabric in acidic medium.
\end{abstract}

Keywords: Cotton Woven Fabric, Titanium Dioxide $\left(\mathrm{TiO}_{2}\right)$, Exhaustion Method, Tensile Strength

\section{Introduction}

The history of clothing is the history of civilization. By the development of science and technology, peoples begin to use cloth in the form of garments. The development of clothing was depended on the development of fiber, which is the only one raw material of making fabric. Natural fibers such as cotton, silk, wool etc. was the major natural sources for making cloth. Among different types of fibers, cotton receives the supreme places by considering different factors of various fibers. Today, cotton is the most used textile fiber in the world. At present, current market share of cotton fiber is 56 percent for all fibers used for garments and home furnishing. It is generally recognized that most consumers prefer cotton personal care items to those containing synthetic fibers.

Cotton is a natural fiber that comes from the seed pod of the cotton plant and is used to make many fabric types. The fiber is hollow in the center and under the microscope, resembles a twisted ribbon [1]. Cotton can be knit or woven into cloth. The two most common weaves for cotton are plain and twill weave. A plain weave or jersey fabric is used to make a wide range of wearing apparel including blouses, shirts, T shirts, children's wear, swimwear, skirts, ladies hosiery etc. A twill weave is more durable and is found in denim, khaki and gabardine.

Cotton fabric is popular because it's easy to care and comfortable year round. In hot, humid weather, cotton breathes. Cotton fibers can absorb up to 27 times its own weight in water [2]. As the body perspires, cotton fibers absorb the moisture and release it on the surface of the fabric, so it evaporates. In cold weather, if the fabric remains dry, the fibers retain body heat, especially napped fabrics. Another characteristic of cotton fiber is that it can be blended with synthetic fibers such as cotton/polyester, cotton/nylon, 
cotton/acrylic, cotton/wool blends etc. Cotton/polyester blend are the most common. By blending with polyester wrinkles and shrinkage problem of cotton fibers can be reduced. Functional finishes such as mildew, flame and stain resistance have added to cottons appeal.

Another functional finish, anti-ultraviolet finish is also demanded properties on cotton fabric. Too much ultraviolet (UV) ray of sunlight is harmful to human being, especially for human skin. Exposing of UV ray causes sun burn, suntan, skin ageing, eye inflammation and cataract. Excessive exposures of ultraviolet ray damage the DNA of skin cell and results malignant skin cancers. So, to protect the human skin from the excessive exposure of UV ray, anti UV ray finish is necessary on cotton fabric. Titanium dioxide $\left(\mathrm{TiO}_{2}\right)$ and zinc oxide $(\mathrm{ZnO})$ is widely used as ultraviolet protecting agent [3-4]. Because both of these chemicals can effectively absorb, reflect and scatter the UV ray from the exposing sunlight. These particles not only rendering the UV protecting function on cotton fabrics but also affect their properties. Especially cotton fabrics absorbency, $\mathrm{pH}$, hand feel and strength are important requirements for wet processing treatment and in normal uses. A recent work [8], shows that treatment of $100 \%$ cotton knitted fabric with $\mathrm{TiO}_{2}$ increased the fabric strength, impaired the fabric absorbency and kept the fabric $\mathrm{pH}$ in acidic medium. But the performance of titanium dioxide treatment on absorbency, $\mathrm{pH}$ and strength of $100 \%$ cotton woven fabrics are not yet studied in versatile range.

The present investigation deals with the treatment of $100 \%$ cotton woven fabric with titanium dioxide and followed by checking the properties of cotton fabric. In this work normal twill (3 up 1 down) fabric was used as a woven fabric. A chemical can be applied on fabric by either exhaustion method or padding method. Already many research of titanium dioxide treatment have done by padding method. In this investigation, titanium dioxide was applied by exhaustion method by following a recipe to find out effectiveness of exhaustion method for penetration of titanium dioxide particles through fiber chain. After treatment, properties were checked to found the effect of titanium dioxide on cotton woven fabric. Properties mean surface investigation by Scanning Electron Microscopy (SEM), hand feel, strength and extension at break, $\mathrm{pH}$ and absorbency of woven fabrics were checked.

\section{Materials and Methods}

\subsection{Raw Materials}

In this experimental exertion, twill ( 3 up 1 down) fabric was used as woven fabric. The fabric was 200 GSM and made from $100 \%$ cotton 20 's yarn.

\subsection{Chemicals}

The major chemical in this work is titanium dioxide $\left(\mathrm{TiO}_{2}\right.$, Merck Specialities Private Ltd, Mumbai). Besides this, wetting agent (Kieralon XC-J, Mixture of non-ionic surfactants, BASF Auxiliary Chemical Co. Ltd. Germany), sequestering agent (Lufibrol MSD, BASF Auxiliary Chemical Co. Ltd., Germany) and distilled water are also used in this experiment.

\subsection{Machines and Instruments}

The following machines and instruments were used in this experimental work -

a. High temperature high pressure (HT/HP) Sample dyeing machine (Model- Model: KL-T200, Shanghai Nanshi Foreign Economic Cooperation and Trading Co. Ltd., Shanghai, China.)

b. Electrical oven (NOVA

Model no: NTG-221L27, Osaka, Japan)

c. Hand dryer

d. James heal universal strength tester

e. Scanning electron microscope

f. $\mathrm{pH}$ Universal indicator.

\subsection{Application of Titanium Dioxide}

In exhaustion method, woven fabrics were treated with three different quantities of titanium dioxide at $80^{\circ} \mathrm{C}$ for $20 \mathrm{~min}$ in the presence of wetting agent and sequestering agent in a HT/HP sample dyeing machine. The liquor ratio of exhaustion bath was 1:10. After $20 \mathrm{~min}$ of exhaustion, the titanium dioxide contained fabric was cured at $140^{\circ} \mathrm{C}$ for $10 \mathrm{~min}$ in an electrical oven. Finally treated fabrics were washed at $60^{\circ} \mathrm{C}$ for $20 \mathrm{~min}$ followed by drying. Three different quantities $(0.5 \%, 1 \%$ and $2 \%$ ) of titanium dioxide were used to treat the fabric. As a result three fabric samples were obtained which were treated with different quantities of titanium dioxide.

\subsection{Measurement of Tensile Strength}

Tensile strength and Extension at break of every woven fabric samples were measured with James-Heal Universal strength tester by following the method of ASTM D5034 (Grab test method). Three time readings were taken for each sample and the average was taken as the final value of the tested sample [5].

\subsection{Surface Investigation by Scanning Electron Microscope (SEM)}

The basic function of SEM is to produce an image of three dimensional appearance of any surface structure at micro meter to nanometer scale. In this experimental work, the surface analysis of titanium dioxide treated woven fabric was done by InspectTM scanning electron microscope.

\subsection{Measurement of Absorbency}

Absorbency is one of several factors that influence textile processing such as fabric preparation, dyeing and the application of finishes. In this work, absorbency of the treated and untreated fabric samples was measured by the AATCC test method 79-2007. In the test method of AATCC 79-2007, a drop of water is allowed to fall from a fixed height onto the taut surface of the test specimen. The time required for the water drop to disappear is measured and recorded as wetting time. In this experimental work, the testing temperature was 
$22^{\circ} \mathrm{C}$ to $24^{\circ} \mathrm{C}$. Five time readings were taken for each sample and the average was considered for the final wetting time of the tested specimen. The shorter the average time, the more absorbent the fabric [6].

\subsection{Measurement of Fabric $p^{H}$}

$\mathrm{P}^{\mathrm{H}}$ is a dominant factor to determine the use of a fabric material in daily life. Extreme acidity or basicity is not accepted. To make a quantitative determination of textile fabric $\mathrm{pH}$, the chemicals which influence $\mathrm{pH}$ must be removed from the textile specimen, collected as water extract and then accurately measured by a $\mathrm{pH}$ indicator. In this experimental work, $\mathrm{pH}$ of the titanium dioxide treated and untreated woven fabrics were measured by AATCC test method 81-2006. In the test method of AATCC 81-2006, the textile specimen (10 gm) is boiled in distilled water. The water extract is cooled to room temperature and the $\mathrm{pH}$ is determined by $\mathrm{pH}$ Universal Indicator. In this experimental work, the testing temperature was $22^{\circ} \mathrm{C}$ to $24^{\circ} \mathrm{C}$. Three time readings were taken for each sample and the average was considered for the final $\mathrm{pH}$ of the tested specimen [7].

\section{Results and Discussion}

\subsection{Observation of Fabric Appearance}

After visual investigation the surface of the treated fabrics, it is obvious that the surface is rough and not smooth than the untreated fabric. Fabric surface becomes harsh and powdery in when compared with original untreated fabric samples. The harshness and powdery affect are increased with the increases of amount of titanium dioxide.

\subsection{Surface Investigation of Treated and Untreated Fabric Samples by SEM}

The SEM images of woven fabric treated with different concentration of titanium dioxide are given below.

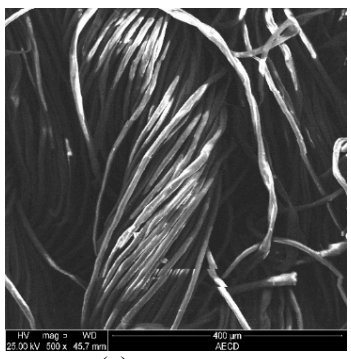

(a)

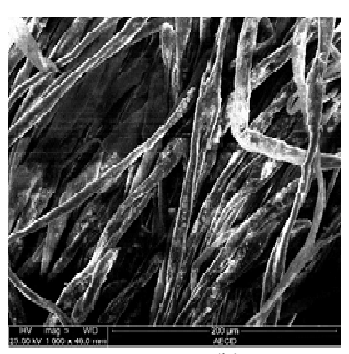

(b)

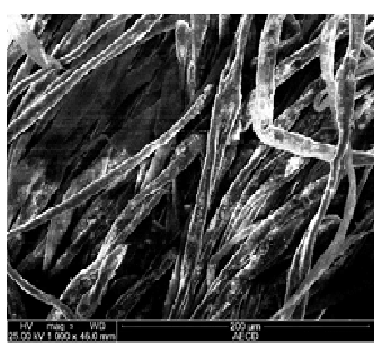

(c)

Figure 1. SEM (Scanning Electron Microscope) image of untreated (a) treated with $1 \% \mathrm{TiO}_{2}(\mathrm{~b})$ and treated with $1 \% \mathrm{TiO}_{2}(\mathrm{c})$ woven fabric
Figures 1 shows the fiber surface topography of the woven fabric samples after 500 times of magnification. By comparing the three images we can see that the untreated fiber surface (a) is smooth and delicate. But in treated fabric (b \& c) it is thoroughly possible to recognize the $\mathrm{TiO}_{2}$ particles on the surface of sample. The $\mathrm{TiO}_{2}$ particles are well dispersed on the fiber surface of the treated fabric and in some areas some aggregated $\mathrm{TiO}_{2}$ particles are still visible. The white and bright appearance of the treated fabric SEM image proves the presence of white $\mathrm{TiO}_{2}$ particles on the fabric surface.

\subsection{Effect on Tensile Strength}

Comparative values of tensile strength are shown in figure 2 and extensions at breaking point are shown in figure 3 . The data express that tensile strength of treated woven fabric is more than the untreated fabric. Tensile strength increased rapidly in case of $0.5 \%$ and $1 \%$ titanium dioxide treated fabric. In case of $2.0 \%$ treated fabric, tensile strength increased slightly than others samples. From the figure 2 it can be concluded that treatment of $100 \%$ cotton woven fabric with $\mathrm{TiO}_{2}$ will enhance the tensile strength of woven fabric. From the figure 3 , it reveals that, extension at breaking point of the treated fabric decreased gradually than the untreated fabric.

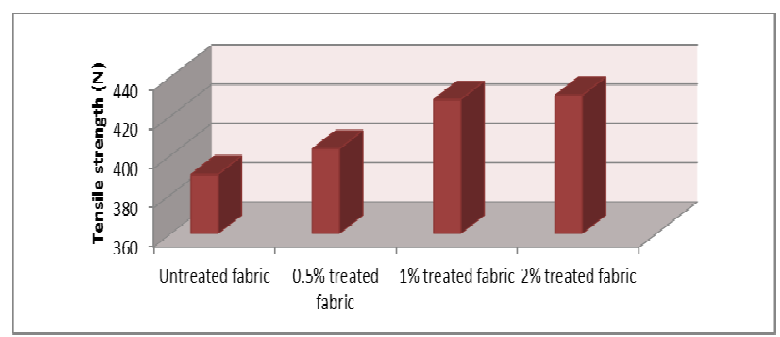

Figure 2. Effect of $\mathrm{TiO}_{2}$ treatment on tensile strength of woven fabric.

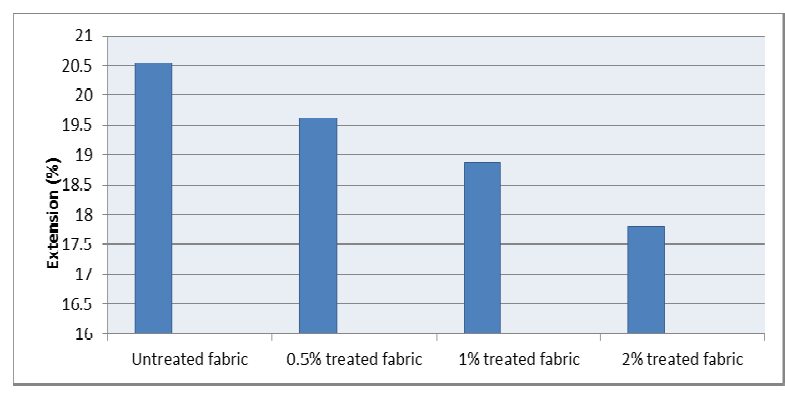

Figure 3. Effect of $\mathrm{TiO}_{2}$ treatment on tensile strength of woven fabric.

\subsection{Absorbency of the Treated and Untreated Fabric Samples}

The figure 4 represents the comparative study of wetting time of $\mathrm{TiO}_{2}$ treated and untreated woven fabrics. The graph reveals that, titanium dioxide impaired the absorbency of woven fabric. Application of $\mathrm{TiO}_{2}$ increases the wetting time of all samples. Wetting time of all samples increases gradually with the increasing amount of $\mathrm{TiO}_{2}$. 


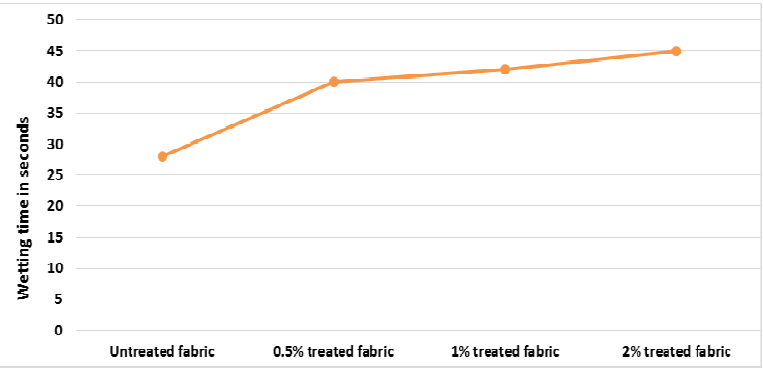

Figure 4. Effect of $\mathrm{TiO}_{2}$ treatment on wetting time of treated and untreated woven fabrics.

\section{5. pH of the Treated and Untreated Fabric Samples}

From the figure 5, it is obvious that presence of titanium dioxide makes the fabrics slightly acidic. In the case of untreated fabric the $\mathrm{pH}$ was 8.5 i.e. slightly alkaline. But treatment with titanium dioxide shifts the $\mathrm{pH}$ to the neutral condition and it reaches to the $\mathrm{pH}$ value 7 in fabrics which were treated with $1.0 \%$ and $2.0 \%$ titanium dioxide respectively.

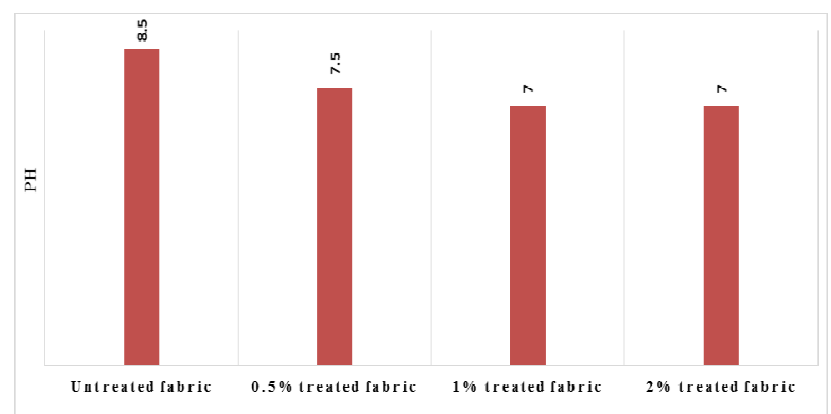

Figure 5. Effect of $\mathrm{TiO}_{2}$ treatment on $\mathrm{pH}$ of treated and untreated woven fabrics.

\section{Conclusion}

Treated fabric surfaces become harsh and powdery due to the presence of titanium dioxide. Fabrics surfaces lose its smoothness in compared with untreated fabric. From scanning electron microscopy, it is obvious that titanium dioxide particles remain on treated fabric polymer chain. It clarifies that treatment by exhaustion method at $80^{\circ} \mathrm{C}$ capable of penetrating titanium dioxide particles through polymer chains of cotton fiber. Treatment with titanium dioxide increased the tensile strength of twill woven fabric and extension at breaking point decreased. Treatment with titanium dioxide impaired the absorbency of twill fabric. The $\mathrm{pH}$ of the treated twill fabric was found in slightly acidic medium.

\section{References}

[1] Cotton: The Most Popular Fabric in the World, Sewing and Craft Alliance.

http://www.sewing.org/files/guidelines/4_105_cotton.pdf (Accessed on June 01, 2013)

[2] Allen, H. Charles, 1999, Cotton in Absorbent Cores, Nonwovens World. Nonwovens World, pp: 71-78.

[3] Saravanam, D., 2007. UV protection textile materials. Autex Research Journal, (7)1, pp: 53-62.

[4] Li, H., P. Deng, H. and J. Zhao 2009. Performance research of polyester fabric treated by nano titanium dioxide anti ultraviolet finishing. International Journal of Chemistry, (1)1, pp: $57-62$.

[5] ASTM D5034 - 09, Standard test method for breaking strength and elongation of textile fabrics (grab test), American standard and testing materials, U.S.A, 2013.

[6] AATCC Test Method 79, Absorbency of Textiles, American Association of Textile Chemists and Colorists,AATCC Technical Manual, Research Triangle Park, North Carolina, U.S.A, 2009

[7] AATCC Test Method 81-2006, $\mathrm{pH}$ of the Water-Extract from Wet Processed Textiles, American Association of Textile Chemists and Colorists, AATCC Technical, Research Triangle Park, North Carolina, U.S.A, 2006

[8] Rahman, M., Solaiman, and K. Elias. 2014. Effect of titanium dioxide treatment on the properties of $100 \%$ cotton knitted fabrics. American journal of engineering research, (3)9, pp: 87-90. 